\title{
A new degree six modified chordal ring network topology
}

\begin{abstract}
The performance of a parallel or distributed network depends on the design of its interconnection topology. One good network interconnection topology that has been the focus of various researchers is the chordal ring. In this paper, a new degree six modified chordal ring is presented, the optimised degree six 3-modified chordal ring (CHR6o3), with the aim of comparing its performance parameters in terms of optimal diameter and optimal average path length to existing degree six chordal rings. Formulae to generate the data for each different chordal ring were derived from its corresponding tree visualisation or used from previous work. Network sizes tested were from 1200 to 12000 nodes. Large networks of CHR6o3 were shown to perform better than those of previous degree six chordal rings. This gives CHR6o3 an added advantage for its implementation in large distributive networks, such as Fibre to the Home (FTTH) networks, since it offers redundancies at higher network layers.
\end{abstract}

Keyword: Degree six chordal rings; Large networks; Optimal average path length; Optimal diameter 